\title{
Valuasi Jasa Ekosistem Hutan Tropis di Kalimantan Timur dengan Metode Benefit Transfer
}

\author{
Ecosystem Services Valuation for East Kalimantan Tropical Forest by Using Benefit \\ Transfer Method
}

\author{
Nuzula Elfa Rahma ${ }^{1^{*}}$, Erna Rositah ${ }^{2}$, Dwi Agung Pramono ${ }^{3}$, Dyah Widyasasi ${ }^{3}$, Fariyanti $^{4}$ \\ ${ }^{1}$ Program Studi Pengelolaan Lingkungan, Politeknik Pertanian Negeri Samarinda, Indonesia. \\ ${ }^{2}$ Program Studi Pengelolaan Hutan, Politeknik Pertanian Negeri Samarinda, Indonesia. \\ ${ }^{3}$ Program Studi Teknologi Geomatika, Politeknik Pertanian Negeri Samarinda, Indonesia. \\ ${ }^{4}$ Program Studi Akuntansi, Politeknik Negeri Samarinda, Samarinda, Indonesia \\ *Corresponding author: elfarahma@gmail.com
}

\begin{abstract}
ABSTRAK
Ekosistem hutan hujan tropis merupakan sumber kehidupan dan penghidupan bagi masyarakat Kalimantan Timur. Sayangnya keberadaan hutan di Kalimantan Timur sering hanya dilihat dalam perspektif ekonomi saja. Untuk itu perlu adanya studi untuk mengetahui nilai manfaat jasa ekosistem yang dimiliki oleh hutan tropis di Kalimantan Timur secara menyeluruh bukan hanya aspek ekonomi saja, tetapi juga aspek ekologis dan sosial. Dengan tujuan itulah, penelitian ini dilakukan. Metode valuasi yang digunakan adalah metode benefit transfer dengan memanfaatkan database valuasi jasa ekosistem TEEB (The Economics of Ecosystems and Biodiversity), serta data luasan hutan Kalimantan Timur. Hasil penelitian ini menunjukkan bahwa nilai total ekonomi (Total Economic Value/TEV) ekosistem hutan tropis di Kalimantan Timur adalah sebesar 90.806.238.765 USD/tahun. Nilai TEV tersebut mencakup nilai manfaat jasa pendukung sebesar $0,24 \%$, jasa penyediaan sebesar $45,11 \%$, jasa pengaturan sebesar $17,31 \%$, dan jasa kultural sebesar $37,34 \%$.
\end{abstract}

Kata kunci: jasa ekosistem, hutan hujan tropis, Kalimantan Timur, valuasi, TEEB database

\begin{abstract}
Tropical forest ecosystem has become a primary resource for the sustainability of life and livelihood for the inhabitants of East Kalimantan. Unfortunately, the forest ecosystem existence is rarely appreciated from the perspectives other than the economic. Therefore, it is necessary to establish a study that aims to investigate the benefit of the East Kalimantan tropical forest ecosystem in terms of a tangible value, which encompasses economic, ecological, and societal aspects. The method undertaken in this study is the benefit transfer method, in which TEEB (The Economics of Ecosystems and Biodiversity) ecosystem services valuation database is employed as the reference. The study also takes into account the latest data of the remaining forest area as the valuation variable. The Total Economic Value (TEV) of the ecosystem services provided East Kalimantan accounts as 90.806.238.765 USD/year, which covers the benefit from supporting services $(0,24 \%)$, provisioning services $(45,11 \%)$, regulating services $(17,31 \%)$, and cultural services $(37,34 \%)$.
\end{abstract}

Keywords: ecosystem services, tropical rainforest, East Kalimantan, valuation, TEEB database

\section{PENDAHULUAN}

Ekosistem hutan hujan tropis di pulau Kalimantan diperkirakan merupakan salah satu hutan hujan tertua di dunia, dan diperkirakan telah berumur 140 juta tahun (Leeder et al., 2016). Hutan hujan tropis pulau Kalimantan selama berabad-abad telah menarik minat masyarakat dunia. Sejarah mencatat, sejak dua ribu tahun lalu, masyarakat dari berbagai belahan dunia sudah menginjakkan kaki di Kalimantan, di antaranya adalah pedagang dari pulau Jawa, Cina, India, Arab dan Mesir Kuno. Jauh sebelum penjajah Portugis memasuki wilayah nusantara (Blair dkk, 1991). Bagi penduduk pulau Kalimantan sendiri, hutan telah menjadi sumber penghidupan serta merupakan bagian tak terpisahkan dari kebudayaan dan falsafah hidup yang membentuk identitas masyarakat pulau Kalimantan. Keberadaan hutan juga 
merupakan penyokong eksistensi sungaisungai besar yang selama berabad-abad menjadi tumpuan masyarakat Kalimantan untuk menjalankan roda perekonomian karena perannya sebagai urat nadi transportasi.

Pasca kemerdekaan Indonesia, hutan Kalimantan tetap menjadi salah satu penyokong utama perekonomian negara sebagai sumber komoditas industri kayu. Selama puluhan tahun, industri ini menjadi pendorong laju deforestasi sebelum akhirnya mengalami penurunan pada dekade belakangan ini. Tercatat di tahun 2019, kinerja industri kayu untuk provinsi Kaltim menurun hingga 49,34\% (Prokal, 2020). Namun bukan berarti tekanan terhadap eksistensi hutan tropis ikut menurun, karena ancaman juga datang dari sektor ekonomi lainnya seperti perkebunan kelapa sawit, tambang, dan alih fungsi lahan lainnya. Berdasarkan dokumen Forest Carbon Partnership Facility (2019) dari tahun 2006 sampai 2016 luasan hutan Kaltim seluas $1,140,536$ ha telah beralih fungsi.

Tentu saja ini menimbulkan ancaman bagi masa depan ekologi Kaltim. Hutan tropis tidak hanya berfungsi sebagai penyedia komoditas bernilai ekonomis saja. Ekosistem hutan Kalimantan memiliki peran penting yang dikenal sebagai jasa ekosistem yang menyentuh segala aspek, baik aspek ekonomi, sosial, maupun ekologis (Bashistha \& Garkoti, 2017). Balvanera, dkk (2016) mendefinisikan jasa ekosistem sebagai segala manfaat yang diterima oleh masyarakat dan merupakan hasil dari interaksi antara manusia dan ekosistem. Meski begitu penting, seringkali aspek pelestarian hutan dikesampingkan. Salah satunya karena manfaat hutan selain aspek ekonomi cenderung bersifat abstrak, tidak seperti nominal uang yang lebih konkrit dan dapat dipertukarkan dengan barang dan jasa.

Oleh karena itu, dalam perumusan kebijakan yang berkaitan dengan perlindungan ekosistem hutan tropis di Kalimantan Timur, diperlukan basis yang valid. Kompleksitas suatu ekosistem menyebabkan sulitnya menilai seberapa besar signifikansinya (Hannah, 2015). Pendekatan yang lazim dilakukan adalah dengan melakukan valuasi. Dimana nilai manfaat suatu ekosistem dipetakan dan dikuantifikasi dalam satuan nilai uang. Dengan demikian, kebijakan tersebut memiliki dasar yang kuat, bahwasana perlindungan suatu ekosistem itu memiliki nilai yang sama pentingnya dengan perekonomian. Atas dasar pemikiran tersebut, penelitian ini dilaksanakan dengan tujuan untuk mengetahui nilai manfaat ekosistem hutan tropis di Kalimantan Timur dengan pendekatan valuasi jasa ekosistem.

\section{METODE PENELITIAN}

Valuasi jasa ekosistem untuk hutan tropis dalam studi ini menggunakan metode benefit transfer. Dimana dalam metode ini valuasi suatu jasa ekosistem untuk ekosistem hutan tropis di Kaltim didasarkan pada hasil penelitian yang telah ada sebelumnya (Johnston dkk, 2015).

Nilai manfaat dari jasa ekosistem diestimasi dengan menggunakan database valuasi lingkungan bertajuk The Economics of Ecosystems and Biodiversity atau TEEB (Van der Ploeg dan de Groot, 2010), yang merupakan inventori valuasi jasa ekosistem di seluruh dunia. Angka valuasi dari database kemudian disesuaikan untuk tahun 2019 , dengan asumsi discount rate sebesar $3 \%$ per tahun. Agar lebih akurat, maka studi yang digunakan sebagai referensi adalah studi dengan area paling mirip karakteristiknya dengan Kalimantan Timur (dari sisi lokasi, negara, dan tipe ekosistem). Berikut adalah kategori jasa ekosistem yang diperhitungkan dalam studi ini (Tabel 1).

Acuan tutupan hutan di Kalimantan Timur didasarkan pada data tahun 2017 yaitu $6,583,879$ ha (FCPF, 2019). Tutupan hutan ini meliputi berbagai tipe kawasan hutan serta lahan non-hutan namun masih memiliki tutupan hutan. Dari data luasan hutan tersebut, kemudian dikalkulasi nilai manfaat jasa ekosistem dari masing-masing kategori. Nilai Total Economic Value (TEV), atau seluruh nilai manfaat dari hutan tropis Kaltim merupakan total dari nilai seluruh jasa ekosistem tersebut. 
Tabel 1. Studi acuan yang dipilih dari database TEEB untuk masing-masing jasa ekosistem

\begin{tabular}{|c|c|c|c|c|}
\hline Jasa ekosistem & $\begin{array}{l}\text { Nilai manfaat } \\
\text { setelah } \\
\text { penyesuaian } \\
\text { (USD/ha/tahun) }\end{array}$ & Area & Peneliti & Tahun \\
\hline \multicolumn{5}{|l|}{ Jasa pendukung } \\
\hline $\begin{array}{l}\text { Siklus nutrient } \\
\text { (kesuburan tanah) }\end{array}$ & 52,60 & Guatemala & $\begin{array}{l}\text { Ammour, T., N. } \\
\text { Windervoxhel dan } \\
\text { G. Sencion }\end{array}$ & 2000 \\
\hline Pembentukan tanah & n.a & n.a & n.a & n.a \\
\hline Produksi primer & n.a & n.a & n.a & n.a \\
\hline \multicolumn{5}{|l|}{ Jasa penyediaan } \\
\hline Pangan & 104,49 & $\begin{array}{l}\text { Gunung Leuser } \\
\text { Aceh, Indonesia }\end{array}$ & $\begin{array}{l}\text { Van Beukering, } \\
\text { P.J.H., H.S.J. Cesar } \\
\text { dan M.A. Jansen }\end{array}$ & 2003 \\
\hline Air & 68,32 & Malaysia & Kumari, K & 1996 \\
\hline $\begin{array}{l}\text { Sumberdaya } \\
\text { Genetik (Genepool) }\end{array}$ & $8.339,88$ & Dunia & $\begin{array}{l}\text { Secretariat of the } \\
\text { Convention on } \\
\text { Biological Diversity }\end{array}$ & 2001 \\
\hline Energi & $3.444,33$ & Laos & Rosales, dkk & 2005 \\
\hline Biodiversitas & $24.463,64$ & Dunia & $\begin{array}{l}\text { Secretariat of the } \\
\text { Convention on } \\
\text { Biological Diversity }\end{array}$ & 2001 \\
\hline \multicolumn{5}{|l|}{ Jasa pengaturan } \\
\hline Pengaturan iklim & $7.116,69$ & Dunia & $\begin{array}{l}\text { Secretariat of the } \\
\text { Convention on } \\
\text { Biological Diversity }\end{array}$ & 2001 \\
\hline $\begin{array}{l}\text { Pengaturan aliran } \\
\text { air }\end{array}$ & 94,03 & Malaysia & Kumari, $\mathrm{K}$ & 1996 \\
\hline Penyerbukan & 144,37 & $\begin{array}{l}\text { Sulawesi Tengah, } \\
\text { Indonesia }\end{array}$ & Priess, dkk & 2007 \\
\hline pencegah erosi & $5.504,32$ & $\begin{array}{l}\text { Gunung Leuser } \\
\text { Aceh, Indonesia }\end{array}$ & $\begin{array}{l}\text { Van Beukering, } \\
\text { P.J.H., H.S.J. Cesar } \\
\text { dan M.A. Jansen }\end{array}$ & 2000 \\
\hline Pencegahan banjir & 424,12 & Laos & $\begin{array}{l}\text { Rosales, R.M.P., } \\
\text { dkk. }\end{array}$ & 2003 \\
\hline $\begin{array}{l}\text { Pengendalian } \\
\text { limbah }\end{array}$ & 680,53 & Cambodia & Bann, C. & 1996 \\
\hline \multicolumn{5}{|l|}{ Jasa kultural } \\
\hline Rekreasi & 11,28 & Indonesia & $\begin{array}{l}\text { Walpole, M.J., H.J. } \\
\text { Goodwin and } \\
\text { K.G.R. Ward }\end{array}$ & 2001 \\
\hline Estetika & $13.835,05$ & Israel & $\begin{array}{l}\text { Fleischer, } \mathrm{A} \text { and } \mathrm{Y} \text {. } \\
\text { Tsur }\end{array}$ & 2004 \\
\hline Ekowisata & $2.393,16$ & India & Verma, M. & 2000 \\
\hline Spiritual & 8,35 & Spanyol & $\begin{array}{l}\text { Brenner-Guillermo, } \\
\text { J. }\end{array}$ & 2004 \\
\hline
\end{tabular}




\section{HASIL DAN PEMBAHASAN}

Berikut adalah hasil valuasi dari jasa ekosistem yang melingkupi jasa pendukung, penyediaan, pengaturan, dan kultural.

\section{Jasa pendukung}

Jasa ini merupakan jasa ekosistem yang paling mendasar, karena merupakan penopang dari kelangsungan jasa ekosistem yang lain yakni penyediaan, pengaturan dan kultural. Millennium Ecosystem Assessment (2005) sesungguhnya merangkum setidaknya ada tiga jasa ekosistem yang berada pada kategori ini, yaitu siklus nutrien yang berperan dalam menjaga kesuburan tanah, pembentukan tanah, dan produksi primer. Akan tetapi database TEEB saat ini hanya memiliki data studi untuk penelitian terkait valuasi siklus nutrien saja. Adapun valuasi untuk jasa ekosistem ini memberikan estimasi sebesar 214,8 juta USD/tahun (Tabel 2) atau setara dengan 3,11 triliun rupiah/tahun.

\section{Jasa penyediaan}

Jasa ini merupakan jasa ekosistem yang langsung dirasakan manfaatnya oleh manusia. Oleh karena itu signifikansinya terhadap perekonomian cenderung sangat besar (Hendrikson \& Sanerson, 2017; Hannah, 2015; Gray, 2018), dengan nilai valuasi yang dapat mencapai milyaran USD per tahun. Dalam studi ini, jasa ekosistem yang diperhitungkan dalam valuasi jasa penyediaan terdiri dari enam jasa (Tabel 2). Total nilai manfaat untuk jasa penyediaan adalah senilai 40,9 milyar USD. Dengan energi mencakup $51,84 \% \%$ dari total nilai tersebut. Diikuti oleh sumberdaya genetik yang mencapai $41,04 \%$.

Penyediaan air sesungguhnya memiliki nilai yang cukup besar yaitu 99,14 juta USD, namun proporsinya sangat kecil yaitu $0,24 \%$. Mengapa ada kesenjangan yang cukup besar antara nilai jasa ekosistem tersebut? Alasannya terkait dengan metode kuantifikasi yang tidak lepas dari bias persepsi. Untuk air, pangan, dan bahan mentah, metode kuantifikasinya didasarkan pada ruang lingkup ekonomi lokal, sehingga harga barang yang menjadi acuan adalah harga di pasar lokal. Sementara untuk sumberdaya genetik dan energi, acuan dalam valuasi adalah perdagangan internasional, dimana perusahaan-perusahaan multi-nasional, terutama perusahaan yang bergerak di bidang energi dan farmasi, ikut andil di dalamnya (Secretariat of the Convention on Biological Diversity, 2001).

Persepsi masyarakat lokal relatif lebih sederhana. Masyarakat lokal lebih berfokus pada apa manfaat yang diberikan dalam terma "saat ini". Dengan kata lain, kurang terlintas adanya ide untuk melihat potensi profit yang lebih besar di masa depan. Di samping itu, relasi sosial pada lingkup ekonomi lokal juga lebih rekat, sehingga dalam interaksi ekonomi, para pelakunya lebih memprioritaskan terpeliharanya harmoni sosial. Tidak demikian halnya dengan valuasi energi dan sumberdaya genetik. Dalam konteks pasar internasional yang berbasis industri, valuasi dapat lebih membengkak nilainya karena industri cenderung berorientasi profit yang sebesarbesarnya. Terutama untuk komoditas bahan bakar (energi), dan obat-obatan serta bahan kimia (sumber daya genetik).

\section{Jasa pengaturan}

Jasa ini merupakan elemen yang sangat substansial dalam peran penting hutan. Dalam kaitannya dengan mitigasi perubahan iklim, hutan menyimpan cadangan karbon yang sangat besar. Hutan juga memiliki fungsi penting dalam siklus hidrologi, pencegah erosi dan banjir, serta fungsi penting lainnya (Seidl, 2019). Dalam studi ini, kategori jasa pengaturan meliputi enam aspek seperti dapat dilihat pada Tabel 2. Valuasi untuk jasa pengaturan mencapai 15,72 milyar USD/tahun. Pencegahan erosi mengambil porsi hingga 66,09\% dari keseluruhan nilai valuasi jasa pengaturan. Lalu diikuti pengaturan iklim sebesar $17,47 \%$.

Dapat dilihat bahwa pencegahan erosi sangat mendominasi. Ini erat kaitannya dengan nilai manfaat pencegahan erosi yang dijadikan acuan. Nilai acuan untuk pencegahan erosi didasarkan pada studi Van Beukeuring dkk (2003) dengan menggunakan metode avoided cost yang basisnya adalah kerugian yang muncul akibat erosi. Dalam studi tersebut, erosi berdampak pada beragam sektor, yang mencakup pertanian, kehutanan, dan pariwisata. Ditambah lagi, erosi juga menyebabkan degradasi tanah yang sulit direhabilitasi. Hal ini menyebabkan nilai valuasi untuk jasa pencegahan erosi sangat 
besar. Dan memang dari sisi masyarakat lokal di sekitar hutan tersebut, bencana erosi lah yang memberikan dampak kerugian yang paling signifikan.

\section{Jasa kultural}

Jasa ekosistem ini merupakan manfaat yang bersifat non-material akan tetapi sangat esensial keberadaannya.
Untuk dapat bertahan hidup, manusia perlu memenuhi kebutuhan pangan, sandang, dan papan. Ini merupakan kebutuhan yang bersifat fisik. Akan tetapi hidup berkualitas juga ditandai oleh kesehatan mental yang prima, baik di tingkat individu maupun dalam hubungan sosial. Disinilah jasa kultural mengambil peran.

Tabel 2. Hasil valuasi jasa ekosistem hutan tropis di provinsi Kalimantan Timur

\begin{tabular}{|c|c|c|}
\hline Jasa ekosistem & $\begin{array}{l}\text { Nilai Manfaat } \\
\text { (USD/tahun) }\end{array}$ & Persentase \\
\hline \multicolumn{3}{|l|}{ Jasa pendukung } \\
\hline siklus nutrient (kesuburan tanah) & 214.766 .133 & $100 \%$ \\
\hline Pembentukan tanah & n.a & - \\
\hline Produksi primer & n.a & - \\
\hline Total & 214.766.133 & \\
\hline \multicolumn{3}{|l|}{ Jasa penyediaan } \\
\hline Pangan & 644.168 .974 & $1,57 \%$ \\
\hline Air & 99.138 .757 & $0,24 \%$ \\
\hline Sumberdaya Genetik (Genepool) & 16.812.919.921 & $41,04 \%$ \\
\hline Energi & 21.233 .972 .939 & $51,84 \%$ \\
\hline Biodiversitas & 575.845 .522 & $1,41 \%$ \\
\hline Bahan mentah & 1.596.327.302 & $3,90 \%$ \\
\hline Total & 40.962 .373 .415 & \\
\hline \multicolumn{3}{|l|}{ Jasa pengaturan } \\
\hline Pengaturan iklim & 2.746 .135 .931 & $17,47 \%$ \\
\hline Pengaturan aliran air & 189.564 .818 & $1,21 \%$ \\
\hline Penyerbukan & 431.803 .709 & $2,75 \%$ \\
\hline pencegah erosi & 10.390 .384 .511 & $66,09 \%$ \\
\hline Pencegahan banjir & 975.167 .316 & $6,20 \%$ \\
\hline Pengendalian limbah & 987.532 .964 & $6,28 \%$ \\
\hline Total & 15.720 .589 .249 & \\
\hline \multicolumn{3}{|l|}{ Jasa kultural } \\
\hline Rekreasi & 22.741 .175 & $0,07 \%$ \\
\hline Estetika & 29.347 .745 .567 & $86,55 \%$ \\
\hline Ekowisata & 4.517 .508 .288 & $13,32 \%$ \\
\hline Spiritual & 20.514 .938 & $0,06 \%$ \\
\hline Total & 33.908 .509 .968 & \\
\hline Total Economic Value & 90.806 .238 .765 & \\
\hline
\end{tabular}


Jasa kultural meliputi empat aspek seperti yang dapat dilihat di tabel 2. Total nilai manfaat jasa kultural mencapai 29,35 milyar USD, di mana estetika mencakup $86,55 \%$ dari keseluruhan total nilai manfaat dari jasa kultural. Estetika mendapat porsi yang cukup besar, salah satunya adalah karena nilai manfaat per ha/tahun cukup besar bahkan melampaui nilai pengaturan iklim yang nilainya hanya $51.4 \%$ dari nilai manfaat jasa estetika.

Serupa dengan valuasi jasa penyediaan, ada bias persepsi yang menjadi faktor. Valuasi manfaat estetika didasarkan pada studi acuan yang berlokasi di negara maju, dengan tingkat pendidikan yang sangat baik, serta kesejahteraan di atas rata-rata masyarakat dunia. Sehingga masyarakatnya lebih memiliki tingkat apresiasi yang tinggi terhadap nilai estetika.

Dengan menjumlahkan seluruh nilai manfaat dari ekosistem hutan tropis di Kaltim, maka didapat nilai TEV mencapai 90,80 milyar USD atau setara dengan 1.316,69 trilyun rupiah per tahun. Hal ini tentu saja, dengan asumsi bahwa sejak tahun 2016, laju deforestasi adalah sebesar $0 \%$ per tahun.
Adapun proporsi masing-masing kategori jasa ekosistem berdasarkan besarnya nilai manfaat dapat dilihat pada Gambar 1 di bawah.

Nampak bahwa jasa penyediaan mengambil porsi paling besar yaitu $45,11 \%$. Sementara kategori jasa pendukung hanya mengambil porsi $0,24 \%$. Meski demikian, hasil tersebut bukan merupakan indikasi bahwa manfaat yang bersifat fisik/material, atau yang dapat berdampak langsung pada ekonomi (tangible), memang memegang peranan paling utama. Ada faktor kesenjangan dan ketidakpastian yang masih cukup besar terkait valuasi jasa ekosistem yang bersifat abstrak. Faktor tersebut dikontribusi oleh kelemahan dalam metode valuasi jasa ekosistem itu sendiri, yang masih menyisakan ruang besar untuk aspek ketidakpastian. Sehingga pada dasarnya proses kuantifikasi hanya dapat memetakan manfaat jasa ekosistem secara parsial bahkan hanya sebagian kecil saja.

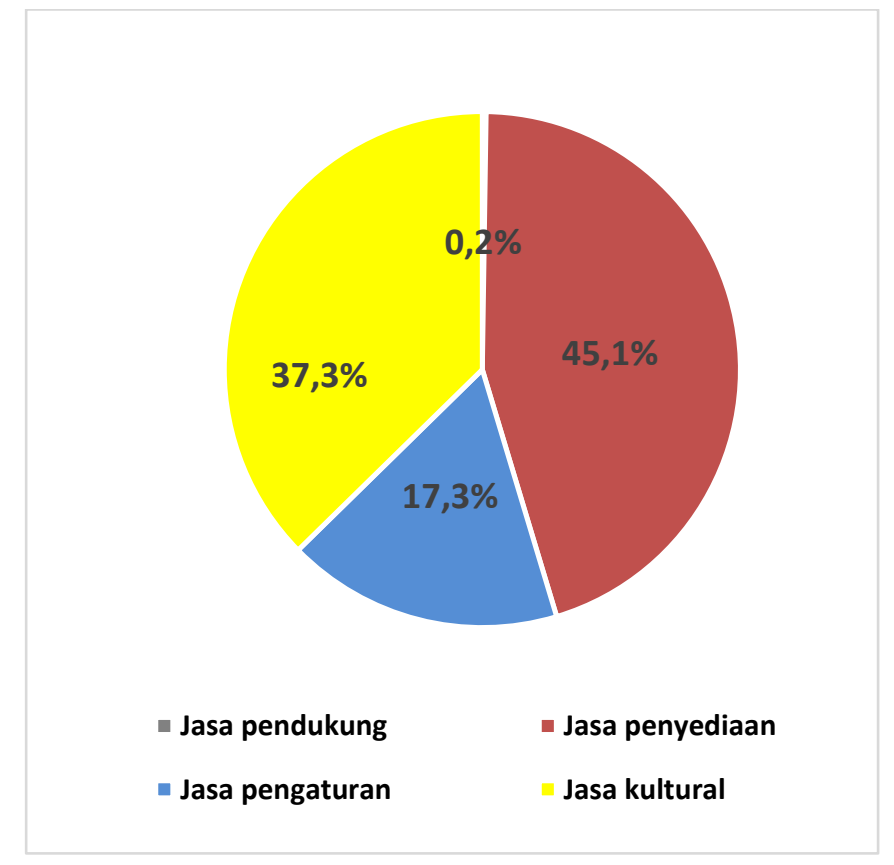

Gambar 1. Proporsi dari masing-masing kategori jasa ekosistem terhadap TEV 


\section{KESIMPULAN}

1. Jasa pendukung memiliki nilai manfaat sebesar 214,77 juta USD/tahun atau setara dengan 3,11 trilyun rupiah/tahun. Namun demikian, pemetaan nilai manfaat untuk kategori ini hanya terdiri dari jasa siklus nutrien saja.

2. Jasa penyediaan memiliki nilai manfaat sebesar 40,96 milyar USD/tahun atau setara dengan 593,95 trilyun rupiah/tahun. Dalam kategori ini, penyediaan energi merupakan jasa ekosistem yang nilai manfaatnya paling besar yaitu mencapai $51,84 \%$.

3. Jasa pengaturan memiliki nilai manfaat sebesar 15,72 milyar USD/tahun atau setara dengan 227,95 trilyun ru[iah/tahun. Dalam kategori ini, pencegahan erosi merupakan jasa ekosistem yang nilai manfaatnya paling besar yaitu mencapai $66,09 \%$.

4. Jasa kultural memiliki nilai manfaat sebesar 33,91 milyar USD/tahun atau setara dengan 491,67 trilyun rupiah/tahun. Dalam kategori ini, estetika merupakan jasa ekosistem yang nilai manfaatnya paling besar yaitu mencapai $86,55 \%$.

5. Total Economic Value (TEV) untuk jasa ekosistem hutan tropis di provinsi Kalimantan Timur adalah sebesar 90,81 milyar USD/tahun atau setara dengan 1.316.69 trilyun rupiah per/tahun. Dari nilai tersebut, jasa pendukung mengambil porsi sebesar $0,24 \%$, jasa penyediaan sebesar $45,11 \%$, jasa pengaturan sebesar $17,31 \%$, dan jasa kultural sebesar $37,34 \%$.

\section{DAFTAR PUSTAKA}

Bashistha, M., \& Garkoti, S.C. 2017. Assessing the Provisioning Services of Forest Ecosystem in a Bhuj Forest, Gujarat. Applied Ecology and Forestry Science, 2(1), 1-4.

Blair, L Helmi, R. dan Lueras, L. 1991. River of Gems. Image Network Indonesia.

Forest Carbon Partnership Facility. 2019. Emission Reductions Program Document (ER-PD). East Kalimantan
Jurisdictional Emission Reductions Program, Indonesia.

Gray, M. 2018. Chapter 1 - Geodiversity: The Backbone of Geoheritage and Geoconservation. In Reynard, E., \& Brilha, J (eds). Geoheritage, 1325. doi:10.1016/b978-0-12-8095317.00001-0

Hannah, L. 2015. Ecosystem Change. Climate Change Biology, 103133. doi:10.1016/b978-0-12-4202184.00005-6

Hendrickson, J., \& Sanderson, M. 2017. Perennial-Based Agricultural Systems and Livestock Impact on Soil and Ecological Services. Soil Health and Intensification of Agroecosytems, 151-171. doi:10.1016/b978-0-12805317-1.00007-5

Johnston, R.J., Rolfe,J., Rosenberger, R.S., \& Brouwer, R. 2015. Introduction to Benefit Transfer Methods: Chapter 2. In Johnston, R.J., Rolfe, J., Rosenberger, R., Brouwer, R. (Eds.) Benefit Transfer of Environmental and Resource Values: A Guide for Researchers and Practitioners. Springer, Netherlands.

Leeder, A.,Brown, A., Coleman, G., Digby, B., Owen, G., Davis, V. 2016. WJEC GCSE Geography. Hodder Education. pp. 199 ISBN 978-1-47186130-7.

Millennium Ecosystem Assessment, 2005. Ecosystems and Human Well-being: Synthesis. Island Press, Washington, DC.

ProKal. 2020. Industri Kayu Kian Tergerus, Bisnis Alat Angkutan Membaik. https://kaltim.prokal.co/read/news/366 791-industri-kayu-kian-tergerusbisnis-alat-angkutan-membaik.html. Diakses pada tanggal 1 Maret 2020.

Secretariat of the Convention on Biological Diversity. 2001. The Value of Forest Ecosystems. SCBD, 67p. CBD Technical Series no. 4, Montreal.

Seidl, R., Albrich, K., Erb, K., Formayer, H., Leidinger, D., Leitinger, G., Tappeinerd, U., Tassere, E., Rammer, W. 2019. What drives the future supply of regulating ecosystem services in a mountain forest landscape? Forest Ecology and 
Management, $\quad 445, \quad 37-$ 47. doi:10.1016/j.foreco.2019.03.047 Van der Ploeg, S. \& R.S. de Groot. 2010. The TEEB Valuation Database - a searchable database of 1310 estimates of monetary values of ecosystem services. Foundation for Sustainable Development, Wageningen, The Netherlands. 